\title{
O BRASIL DO IMPÉRIO À REPÚBLICA: \\ Economia e Política Externa na Transição Hegemônica Mundial
}

\author{
Pedro dos Santos de Borba ${ }^{1}$
}

\begin{abstract}
Resumo
Nosso problema de pesquisa é a construção das estruturas hegemônicas norteamericanas no Brasil, do ponto de vista da economia e da política externa, e o processo de recentramento hegemônico pelo qual o país passou durante a República dos cafeicultores. Assim, preocupamo-nos não só em elaborar conceitualmente os pilares da hegemonia norte-americana, mas também em (1) analisar historicamente seu amadurecimento e (2) compará-los com os pilares da hegemonia britânica, que balizaram a inserção internacional brasileira no século XIX, e (3) refletir sobre a repercussão social dessa transição hegemônica. As conclusões do artigo podem ser resumidas no que segue. Por razões geopolíticas e econômicas, os Estados Unidos consolidaram sua hegemonia no Brasil com antecedência à universalização de suas estruturas de poder para todo o sistema-mundo, o que propiciou ao menos três transformações estruturais na sociedade brasileira. A primeira foi a consolidação da hegemonia da elite paulista e cafeicultora, que, em um processo de desenvolvimento associado aos Estados Unidos, tomou as rédeas do desenvolvimento nacional e capitaneou nas décadas seguintes a industrialização do país. A segunda foi a transição no paradigma de transportes, abandonando o padrão ferroviário (movido a carvão) defendido pelos britânicos e adotando o modelo rodoviário (movido a petroderivados) liderado pelos Estados Unidos. A terceira foi a gradual reconfiguração da polaridade regional da América do Sul, em que a transição hegemônica mundial acarretou um fortalecimento do Brasil, parceiro político-econômico dos Estados Unidos, em detrimento da posição argentina, que se desenvolvera associada ao imperialismo britânico.
\end{abstract}

\section{Palavras-chave}

Transição hegemônica mundial - política externa brasileira - República Velha Estados Unidos

\section{Abstract}

Our research problem is the historical construction of the North American hegemonic structures in Brazil, from the perspective of Brazilian foreign policy and national economy, as well as the process of hegemonic transition that took place during the oligarchic republic. Therefore, we focus on the conceptual framework of this hegemony,

\footnotetext{
${ }^{1}$ Pedro Borba é graduando em Relações Internacionais pela UFRGS e bolsista do Núcleo de Estratégia e Relações Internacionais (NERINT/UFRGS), onde trabalha na área de Segurança Internacional e América Latina. Foi discente-visitante na Faculdade de Letras da Universidade do Porto (Portugal), vice-presidente do Centro Estudantil de Relações Internacionais da UFRGS e é membro do Conselho Executivo da revista discente Perspectiva: Reflexões sobre a Temática Internacional (1983-9707).
} 
but also on: (1) its historical development, (2) the comparison with the structure of British hegemony, which oriented Brazilian international engagement in nineteenth century, and, at last, (3) the social repercussion of this hegemonic transition in Brazil.The article's conclusions can be briefed in what follows. For economic and geopolitical reasons, the United States developed its hegemony in Brazil before they did it globally, what caused three main changes in Brazilian society and economy. The first one was the consolidation of the emerging bourgeoisie originated from Sao Paulo state, that, associated with the North American leadership, assumed the preeminence in national economy and conducted the industrialization along twentieth century. The second was a transition in transportation means, with the substitution of a coal-based matrix of railways inspired in Great Britain for the oil-based highways model supported by the US. The third was a shift in the regional distribution of power in South America, in which the world hegemonic transition engendered the rise of Brazil, strategic partner and associated of United States, and the secular decline of Argentina, whose development was linked to British imperialism.

Key Words

World hegemonic transition - Brazilian foreign policy - oligarchic republic - United States 


\section{Introdução}

O presente artigo se dispõe a estudar o processo de construção da ordem hegemônica centrada nos Estados Unidos a partir das relações internacionais do Brasil; essa proposta implica analisar não só o declínio histórico das estruturas hegemônicas britânicas (baseadas no imperialismo de livre comércio), como também focar a construção das condições objetivas e subjetivas do poder norte-americano. Ainda que se tome como referência a literatura produzida pela Economia Política Internacional (EPI) sobre o tema das transições hegemônicas, fazemo-lo com a finalidade de confrontá-la com as obras clássicas da História da Política Externa Brasileira (HPEB), de autores como Clodoaldo Bueno, Amado Cervo, Luiz Alberto Moniz Bandeira e Eugênio Vargas Garcia. Esse diálogo entre a macrossociologia histórica e a história da política externa tem dois objetivos principais: primeiro, propor novas bases teóricas para compreender nossa inserção internacional, sugerindo, através dos movimentos de longa duração do sistema mundial, quais são os constrangimentos materiais e ideológicos que a política exterior brasileira historicamente enfrentou. Segundo, proporcionar mais substrato histórico à teoria das transições hegemônicas, apresentando o ponto de vista periférico de uma economia primário-exportadora.

Ainda a título de introdução, são necessários dois esclarecimentos: por que “economia e política externa” e o que entendemos por "hegemonia”. Quanto à primeira questão, julgamos que o diálogo entre essas duas esferas, economia e política externa, é pertinente pela proposta do estudo, que trabalha com EPI e HPEB. Ao lidar com transições hegemônicas, trata-se da dinâmica do sistema-mundo capitalista, da capacidade de acumulação de capital e de se fazer dele poder político; ao lidar com 
história da política exterior, trata-se de um encadeamento de decisões políticas e estratégicas que não são tomadas com absoluta autonomia, mas sim imersas em uma estrutura de centro e periferia, na qual há uma interação permanente - constringente porém não determinista - com o interno e o externo. Dessa forma, esses dois níveis operam em duas temporalidades distintas: a economia oferece uma variável mais estrutural, menos suscetível ao personalismo político; já a política externa revela uma maior autonomia em relação aos movimentos de longa duração, podendo oscilar e divergir deles no “tempo curto”. Exemplos desse descolamento entre momento político e transformação estrutural são, como veremos adiante, a euforia pan-americana no imediato pós-1889 ou a "política de prestígio" de Artur Bernardes. Ao invés de contradizerem o processo tectônico de transição hegemônica mundial, tais eventos episódicos nos alertam para a impossibilidade de qualquer “determinismo externo” para tentar explicar a HPEB, que é permeada também pela contingência e pelo personalismo.

A segunda questão concerne à natureza de “hegemonia” e, para situar o debate, é fundamental recorrer ao pensamento político de Antonio Gramsci². Para o pensador italiano, a condição hegemônica se dá para além da capacidade submeter ou dominar, pois "se a força é necessária para a dominação de uma classe, ela não é suficiente, porque é necessária sobretudo a hegemonia, o consenso, como condição essencial ao prosseguimento da obra empreendida com a conquista do poder” (Macciochi, 1975, p.178). Dessa forma, a concepção de hegemonia passou a englobar elementos objetivos

\footnotetext{
${ }^{2}$ Segundo Gramsci (1982), as funções de hegemonia e governo político são dadas por duas vias, a saber: "1) do consenso"espontâneo" dado pelas grandes massas da população à orientação impressa pelo grupo fundamental dominante à vida social, consenso que nasce "historicamente" do prestígio (e, portanto, da confiança) que o grupo dominante obtém, por causa de sua posição e de sua função no mundo da produção; 2) do aparato de coerção estatal que assegura "legalmente" a disciplina dos grupos que não "consentem", nem ativa nem passivamente, mas que é constituída para toda a sociedade, na previsão dos momentos de crise no comando e na direção, nos quais fracassa o consenso espontâneo" (Gramsci, 1982, p. 11).
} 
(econômicos e militares) e subjetivos (ideológicos), que se completam para garantir estabilidade e legitimidade. As leituras posteriores de Gramsci pela EPI irão conceber o caráter consensual da hegemonia como uma capacidade de universalizar o interesse particular e criar com ele a percepção de liderança legítima no sistema inter-estatal (por exemplo, Arrighi, 1996). Assim, o processo de construção das estruturas hegemônicas norte-americanas foi levado a cabo nos dois sentidos: no plano material, através do desenvolvimento de capacidade coercitiva e atratividade econômica; e, no plano subjetivo, por meio da universalização do liberalismo iluminista e das instituições burguesas, evidenciando que “a legitimidade da hegemonia de uma grande potência passa pela criação de uma ideologia política, cujo papel é exatamente o de evitar a transparência da dominação e de apresentá-la como um fato natural ou necessário à existência do conjunto” (Moura, 1985, p.88).

\section{1808-1844: Os três processos da hegemonia britânica}

A primeira metade do século XIX é o período de consolidação e auge da hegemonia britânica na inserção internacional brasileira. Não sem algum grau de arbitrariedade, podemos tomar como referência para tal o período iniciado em 1808 com a transferência da corte de Bragança para o Rio de Janeiro - indo até 1844 -, quando são revogados os Tratados de Comércio, Amizade e Navegação firmados em 1827. Durante essa etapa, os principais eixos de influência inglesa são o político e o comercial, em um contexto de emancipação colonial e de inserção periférica do novo Estado brasileiro na divisão internacional do trabalho. 
Segundo Arrighi (1996), a hegemonia inglesa foi capaz de reestruturar a ordem do sistema mundial graças a três processos históricos paralelos e complementares: (1) a garantia de estabilidade e o fim do caos sistêmico gerado pela disputa hegemônica anglo-francesa, (2) o imperialismo de livre-comércio como novo paradigma de acumulação e (3) a ampliação da "zona de amizade" e de "comportamento civilizado" de modo a incluir as Américas na sociedade européia de nações (Arrighi, 1996, p.4759). Ainda que somente o último deles seja diretamente relacionado às relações internacionais do Brasil, buscaremos uma transposição de tais processos mundiais para nossa realidade de estudo.

A estabilidade sistêmica garantida com o desfecho das Guerras Napoleônicas teve sua repercussão antecipada no Brasil com a vinda da corte portuguesa para o Brasil em 1808. Com a manobra, o Brasil se pôs afastado do teatro europeu de confrontos e reconheceu a supremacia britânica, permitindo relativa superação do ambiente de incerteza e imprevisibilidade política que imperava no Velho Continente. Os conflitos das décadas seguintes, já inseridos no processo de independência, terão um cunho nãosistêmico, e sim periférico (Brasil-Portugal), e enquadrar-se-ão em uma dinâmica hegemônica (mediação inglesa).

O segundo pilar da hegemonia inglesa, o “imperialismo de livre-comércio”, irá se consolidar no Brasil como um desdobramento histórico do primeiro. Ícone da etapa político-comercial da dominação inglesa, o tratado que abrirá o mercado brasileiro às manufaturas britânicas é firmado por D. João VI em 1810, é renovado por seu filho em 1827 e sacramentará o "precoce enquadramento luso-brasileiro no sistema internacional vigente” (Cervo e Bueno, 2008, p.17). Impondo uma tarifa privilegiada sobre as mercadorias inglesas (15\% ad valorem), os Tratados de Amizade, Comércio e 
Navegação serão os principais responsáveis pelos déficits crônicos da balança comercial brasileira no período 1822-1844 (com uma média relativa de 15\%, o valor total é próximo a £15mi). O comércio bilateral com a Grã-Bretanha foi consideravelmente expandido, passando de US\$20mi em 1825 para US\$30mi em 1830, ainda que devamos ter em mente o forte desequilíbrio em desfavor das contas públicas brasileiras (Bueno, 2003, p.33; Cervo e Bueno, 2008, p.55). A penetração do liberalismo comercial na Política Externa brasileira foi um desenvolvimento dialético entre consenso e dominação, no qual se interpenetra o desejo de “independência a qualquer preço" - que movia a elite luso-brasileira à época -, a defesa interna da vocação primárioexportadora do Brasil - combinada com a qualidade e o baixo custo das manufaturas inglesas - e a posição privilegiada de pressão política que os britânicos desfrutaram em 1810, graças à guerra européia, e em 1827, graças ao reconhecimento da independência. Dessa forma, avaliar a projeção do “imperialismo de livre comércio” no período 18081844 impõe admitir que "ao apresentar sua supremacia mundial como encarnação dessa entidade metafísica [o mercado], o Reino Unido logrou ampliar seu poder no sistema interestatal muito além do que era justificado pela extensão e eficiência do seu aparelho coercitivo” (Arrighi, 1996, p.55).

Por fim, o terceiro processo histórico fomentado pela hegemonia britânica é a expansão das comunidades nacionais para os povos da América, e nesse ponto podemos elencar com certa tranquilidade o ano de 1822 como marco de referência. Em uma perspectiva global, o apoio dos ingleses ao princípio das nacionalidades não tinha simplesmente o objetivo anti-colonial de expandir a divisão internacional do trabalho em uma matriz industrial (foco nas independências americanas), mas também o de enfraquecer o conservadorismo legitimista e absolutista da Santa Aliança. Contudo, o 
processo de independência do Brasil esteve distante desse espírito modernizador, sendo antes uma manobra pragmática das elites locais (luso-brasileiras) para se desvincular de laços metropolitanos obsoletos e se associar politicamente ao centro dinâmico do sistema mundial. O radicalismo dessa inversão marcou o início formal do que Amado Cervo chama de "imobilismo diplomático" da Política Externa brasileira, que, na ânsia de se colocar no passo das transformações mundiais, acabou por abrir mão de sua autonomia política e de sua capacidade de barganha (Cervo e Bueno, 2008, p.26), reduzindo sua atuação exterior por três décadas ao “exercício da autonomia possível”. Esse imobilismo seria revertido somente na década de 1840, quando o Império retoma o controle de seu comércio exterior, dando início a uma segunda etapa da hegemonia britânica - centrada então nas altas finanças e no investimento direto.

Ao longo da primeira metade do século XIX, a aproximação político-econômica do Brasil com os Estados Unidos foi parca, tendo estes revelado pouca projeção na América Latina, a qual, quando ocorria, privilegiava regimes republicanos. Segundo Moniz Bandeira (1973), “aos americanos o Império [brasileiro] afigurava-se-lhes como o baluarte dos interesses da Grã-Bretanha na América. Não era de se estranhar, portanto, que suas simpatias se voltassem para a Argentina” (Moniz Bandeira, 1973, p.63). Destarte, o destaque historicamente dado à Doutrina Monroe (1823) é inferido de avaliações ex post, ou seja, por análises que irão situar sua validade cerca de um século adiante, associada ao Corolário Roosevelt. No contexto em que é proclamada, a Doutrina é constrangida pela correlação de forças e instrumentalizada pelo sistema de hegemonia do Reino Unido, uma vez que "era do interesse dos capitalistas ingleses que a potência norte-americana assumisse o papel de polícia internacional, pois estariam protegendo seus interesses” (Bueno, 2003, p.33). A diplomacia de Canning considerou a 
declaração unilateral de Monroe, na circunstância em que foi proclamada, uma vitória britânica, pois garantia, somada à Quádrupla Aliança e ao compromisso francês de nãointervenção na América, certa imunidade das novas nações ao intervencionismo europeu, deixando um importante espaço para o "imperialismo de livre comércio" capitaneado pelo Reino Unido (Arrighi, 2001, p.69; Cervo e Bueno, 2008, p.36-37). A projeção hegemônica estadunidense carecia, em última instância, da maturação histórica de suas condições objetivas, implicando que os "efeitos imediatos [da Doutrina Monroe] quanto à defesa dos novos estados americanos seria de ordem puramente moral. As necessidades econômicas e o peso político e militar limitavam-lhe então a eficácia” (Moniz Bandeira, 1973, p.50)

\section{1844-1870: Autonomia alfandegária e integridade territorial}

O estabelecimento do II Império (1840) e o expiro dos tratados de 1827 (18421844) redesenharam a Política Externa brasileira e sinalizaram uma nova etapa na relação do país com a hegemonia britânica. Readquirindo um grau soberano de capacidade de decisão, o estado brasileiro orientou sua inserção externa em dois eixos principais: a defesa de sua integridade territorial e o exercício da autonomia alfandegária. Por seu turno, o Reino Unido deslocava o eixo de suas importações para seu Império afro-asiático, tendo concentrado no Brasil sua liderança no crédito e na exportação de capitais produtivos, orquestrando, com isso, um ciclo de modernização conservadora no país (Cervo e Bueno, 2008, p. 65-71). Podemos situar essa etapa até 1870, a partir de quando se faz necessário somar a esse quadro um processo de crescente identificação ideológica das elites republicanas e abolicionistas com os 
Estados Unidos, superando o receio geopolítico que marcara a percepção monárquica em relação ao vizinho do norte (Moura, 1985).

A ênfase dada à integridade territorial brasileira se relacionava com as duas grandes portas geoestratégicas da América do Sul, a Bacia do Prata e o Amazonas. Racionando nesses termos, as principais percepções de ameaça vinham, respectivamente, do equilíbrio regional (que culminaria da Guerra de 1865-1870) e na ingerência norte-americana na Amazônia (acicatada pelo ciclo da borracha). Uma vez que a política regional não é nosso foco, dediquemos algumas linhas ao segundo caso, que representa o primeiro contato profundo entre o Brasil e os Estados Unidos, a potência em ascensão.

A pretensão estadunidense na Amazônia se articulava, a partir de 1848, no binômio navegabilidade e colonização, desdobrando-se da dedução de que era mais fácil governá-la de Nova York do que do Rio de Janeiro, devido à facilidade das comunicações marítimas com Belém. As guerras de colonização travadas no Texas e na Califórnia alertavam não só para o precedente, mas também sinalizavam, aos olhos da monarquia brasileira, que “o enriquecimento material dos Estados Unidos exacerbou seu expansionismo e sua belicosidade (Moniz Bandeira, 1973, p.87), o que geraria o primeiro movimento anti-estadunidense do Brasil. A determinação político-militar de abertura do Rio Amazonas ("peacebly if we can, forcebly if we need") afastou ainda mais o II Império da parceria pan-americana, colocando os Estados Unidos ao lado de Solano López na Guerra do Paraguai.

A autonomia alfandegária conquistada em 1844 logo se associou a uma “idéia de construir uma potência econômica”, isto é, recuperar receitas públicas (através da taxação do comércio exterior), industrializar o país (para romper a dependência 
britânica) e investir em infra-estrutura (com capital britânico). As contradições da euforia modernizante lançada pela Tarifa Alves Branco (1845) foram postas com clareza por Amado Cervo:

O pensamento industrialista flui nos debates parlamentares e no Conselho de Estado, quando se examina a lei do orçamento, as propostas de tratados, as pautas de alfândega e outras matérias pertinentes. (...) A proposta de se remediar a sociedade do atraso e da dependência partiu do Estado, e também foi por seus homens sepultada no comodismo ilusório e na fuga para o romantismo das teorias econômicas (Cervo e Bueno, 2008, p.73-77).

Em outras palavras, a inconstância da política comercial não permitiu nem um protecionismo eficiente nem um liberalismo convicto, muito graças à falta de consenso na opinião pública e nas casas parlamentares quanto à validade da vocação agrícola brasileira contra a sedução da indústria (Manzur, 1999, p.36-37). Em termos de hegemonia, essa indecisão reflete um grau de ambivalência do "imperialismo de livre comércio” britânico: a defesa do "livre comércio" defendida pelos ingleses a partir da década de 1840 (e não mais simplesmente imposta) inspirava certa liderança hegemônica nos liberais, enquanto que a "imitação" da liderança industrial e comercial dos britânicos seduzia os protecionistas a seguir o caminho de acumulação de capital via industrialização.

Tendo feito esclarecimentos a respeito das duas principais opções da estratégia brasileira pós-1844 - a saber, a integridade territorial e a autonomia alfandegária -, é necessário abordar a reformulação das estruturas hegemônicas britânicas, que atingiam nesse período seu auge em âmbito mundial com a Guerra da Criméia, a consolidação imperial na Índia e o conflito franco-prussiano (Arrighi, 1996, p.169). No Brasil, a influência dos ingleses estava passando a uma nova fase, sobre a qual iremos nos centrar agora. 
O primeiro ponto é o retrocesso da supremacia comercial dos britânicos, causada tanto pelos surtos de protecionismo como pela maior presença norte-americana, que foram responsáveis pela reversão da balança comercial do Império a partir de 1861. Ainda que o Reino Unido liderasse o comércio exterior brasileiro nesse ano (com 33\% das exportações e 55\% das importações, contra 28\% e 7\% dos Estados Unidos), os Estados Unidos expandiam sua participação - em meio a uma guerra civil - com um desequilíbrio favorável ao Império, conseguindo absorver, já em 1870, 75\% das exportações de café do Sudeste brasileiro (Moniz Bandeira, 1973, p.116-120). Se, por um lado, detectamos o embrião de uma tendência inexorável à transição comercial rumo aos Estados Unidos, vemos, por outro, a musculatura econômica britânica se reafirmar no Brasil, a partir de 1860, pela expansão financeira e creditícia, em um ciclo de exportação de capital que se estenderia até o início do século $\mathrm{XX}$. Os grandes investimentos externos foram essencialmente concentrados em setores ligados ao núcleo primário-exportador, como ferrovias, portos, seguros, telégrafos, bancos, casas importadoras etc. Nesse período, instalam-se no Brasil os principais tentáculos do grande capital britânico, através do London\&Brazilian Bank, do British Bank of South America e do London\&River Plate Bank (Garcia, 2006, p.145-149). Dessa forma, a ascensão do café imbricar-se-ia historicamente a um processo de modernização conservadora, financiada por capital estrangeiro, que fecundaria novos centros urbanos, desenvolveria a plantation cafeeira e a infra-estrutura que lhe suportava, proporcionaria surtos de industrialização e substituiria progressivamente a mão-de-obra escrava pela imigração na segunda metade do século XIX.

O dilema da escravidão no Brasil é paradigmático do processo histórico de longa duração que se operava na orientação externa brasileira. Objeto de intensas pressões 
inglesas ao longo da primeira metade do século XIX, a abolição do tráfico não logrou efetividade antes de 1850, a partir de soluções unilaterais (Bill Aberdeen e Lei Eusébio de Queirós). Paradoxalmente, a ascensão do abolicionismo não se deu associado à GrãBretanha, que o defendia há décadas, mas sim com identidade aos Estados Unidos, que o haviam adotado somente alguns anos antes. Lembrando a argumentação de Arrighi, precisamos admitir que a "escravatura capitalista" significou um pilar importante para os ingleses, já que, em sua ascensão hegemônica, “a escravidão no Novo Mundo solucionou o problema capitalista colonial, numa época em que não havia nenhuma outra solução à vista” (Blackburn apud Arrighi, 1996, p.50). A defesa da mão-de-obra livre vinha impregnada de novos ares, progressistas e republicanos, nascidos da “modernização conservadora” e da Guerra do Paraguai.

Portanto, a carência de coordenação política no caso da escravidão, associado ao sentimento “anti-tratados” pós-1844 (que reverteu a extraterritorialidade, as prerrogativas comerciais e todos demais “privilégios abusivos” dos ingleses), suscitou uma decaída considerável na relação bilateral anglo-brasileira na segunda etapa de sua hegemonia. Como nos lembra Eugênio Vargas Garcia, “na segunda metade do século XIX, a influência política da Grã-Bretanha sobre o Brasil era ínfima se comparada a seus interesses econômicos espalhados por todo o país” (Garcia, 2006, p. 593), ou seja, o alinhamento político estava em recuo paralelo ao do comércio - que juntos haviam caracterizado a primeira etapa da hegemonia britânica no Brasil. A nível político, a segunda etapa deteriorou fortemente a relação bilateral, pela via do conflito diplomático (caso Christie, em 1863) e pela via da intransigência político-militar do Bill Aberdeen (1845), desenrolados na autorização britânica para que sua força naval penetrasse mares territoriais brasileiros e no deslocamento de sua esquadra vinda do Prata (Cervo e 
Bueno, 2008: p.109-128). Contudo, o vigor da penetração econômica britânica de caráter financeiro-creditício na segunda metade do século XIX nos obriga a

distinguir as relações de governo a governo, em que prevaleceu o conflito sobre o entendimento, e as relações de nação a nação, que marchavam para um entrelaçamento crescente e dominante, apenas desafiado no século XIX pela concorrência de norte-americanos, alemães e franceses (Cervo e Bueno, 2008, p.83)

\section{1870-1889 - Manifesto de Itu e as exportações de café}

A Guerra do Paraguai (ou Guerra Grande, 1865-70) teve um impacto contraditório na transição hegemônica de que estamos tratando. Os Estados Unidos haviam apoiado o lado derrotado, mas saíram da Guerra como "líderes morais” do movimento de elite, republicano e abolicionista, que se semeava no Brasil desde a publicação de “O Federalista” em 1840. Do lado britânico, o apoio à Tríplice Aliança render-lhe-ia poucos frutos políticos imediatos. A despeito disso, a City londrina ampliou sua presença financeira com a deterioração das contas públicas brasileiras, em função das despesas de guerra: de 1871 a 1889, foram seis empréstimos contraídos, cujo montante principal se destinava a cobrir déficits e no refinanciamento de dívidas antigas (Doratioto, 2003, p. 147-148)

Em suma, o final do Segundo Reinado (1870-1889) foi um período em que as bases da hegemonia britânica estavam sólidas - seja pelo predomínio naval nos portos brasileiros, seja pela liderança comercial (sobretudo nas importações necessárias à modernização do país), seja pela crescente exportação de capitais (Garcia, 2006, p.145166 e p.275-277). No entanto, esse período marca a ascensão de duas tendências históricas que vão de encontro a essas bases: a primeira é de cunho comercial e político, uma vez que "quanto mais o Brasil passava a depender do café, tanto mais os Estados 
Unidos influenciavam suas decisões” (Moniz Bandeira, 1973, p.117); a partir de 1870, o café brasileiro passaria a entrar sem tarifas alfandegárias no mercado estadunidense. Lembremos, ademais, que a dependência da exportação de café para os Estados Unidos é maior do que a parcela percentual sugere, pois o desequilíbrio positivo na balança comercial com esse país era o que garantia (da década de 1860 em diante) as importações manufaturadas e a obtenção de crédito no Reino Unido. A segunda tendência é de cunho político-ideológico, pois em duas décadas a monarquia sofreu uma corrosão irreversível de sua legitimidade interna, em virtude do fortalecimento político dos militares e dos cafeicultores, combinados ao pan-americanismo, ao republicanismo, ao abolicionismo, ao federalismo e, por fim, à modernização técnico-científica, cujo caráter prático se chocava com a erudição livresca dos bacharéis ibero-americanos.

Esse reajuste da correlação de forças interna tinha uma contrapartida externa muito clara: "somos da América e queremos ser Americanos”, afirmava o Manifesto Republicano de Itu de 1870. Em poucas palavras, os Estados Unidos galvanizavam todas as aspirações de renovação do país. E tal inspiração civilizacional, que associava o pan-americanismo à superação do atraso, ganhará substância histórica graças a duas transformações ocorridas nessas duas décadas (1870-1889), uma de caráter externo e outra no plano interno brasileiro. A nível internacional, precisa-se considerar que o projeto pan-americano sofre uma reformulação importante, abandonando a ênfase jurídico-política das Conferências Americanas do século XIX, cujo excessivo idealismo afastava a inteligência monárquica brasileira, sabidamente pragmática e realista. De 1824 a 1888, portanto, o Brasil absteve-se de tomar assento nas Conferências Americanas (Cervo e Bueno, 2008, p.137-144). Contudo, uma mudança de fundo ocorreria quando 
extraindo forças de ambos os lados, a iniciativa norte-americana, a partir de 1880, embora fizesse algumas concessões aos idealistas, iria trazes o pan-americanismo à realidade, ao tentar convertê-lo no instrumento que viabilizasse o programa de dominação capitalista sobre o continente (Cervo e Bueno, 2008, p.144).

Ao se desvincular da utopia republicana e aproximar-se de uma aliança com os Estados Unidos, o pan-americanismo obtinha crescente respaldo das elites brasileiras, em especial daquelas em ascensão. A visita do Imperador à Exposição Mundial da Filadélfia ganhava uma conotação particularmente simbólica, uma vez que os Estados Unidos - comemorando o centenário de sua Revolução política - mostravam ao Brasil e ao mundo a prosperidade econômica e os triunfos da ciência, do telefone à eletricidade. A esse panorama vem se conjugar uma transformação “interna” ocorrida nas décadas finais do Império, qual seja, um surto manufatureiro na década de 1880. Conforme já tratamos, a indecisão entre protecionismo e livre-cambismo, aliada às vicissitudes do centro industrializado, gerava surtos esporádicos de expansão industrial no Brasil desde a década de 1840. O surto de 1880, por seu turno, encontrou condições históricas que lhe amplificaram a repercussão política: o Brasil crescia, combatia a escravidão e se modernizava, na linha dos Estados Unidos, mas estava preso às estruturas obsoletas da monarquia. A conjuntura internacional e a correlação de forças internas sentenciariam o ocaso do II Império: o processo de modernização econômica estava exigindo sua contrapartida política. Como consequência, 1889 viria reestruturar o Brasil e atualizá-lo ao processo de transição hegemônica, criando aqui uma república federativa ideológica e emocionalmente pan-americana - mas economicamente dependente do Reino Unido. 


\section{1889 - 1914: As concepções pan-americanistas e a I Guerra Mundial}

A virada do século XIX para o XX foi marcada pelo recrudescimento dos "panismos”3, que foram associações ideologizadas entre três fenômenos históricos típicos do período: o nacionalismo, o imperialismo e a ascensão de novos pólos de poder, que vinham desestabilizar o Concerto Europeu de 1815 (Bueno, 2003, p.27-37). Como vimos, os Estados Unidos não havia posto o pan-americanismo nessas bases senão a partir da década de 1880, e foi em 1889 que os militares brasileiros abraçaram radicalmente essa ideologia, trazendo a inspiração estadunidense para a bandeira nacional, para o desenho político da república e para o novo nome do país.

A americanização do Brasil significava, para os homens que assumiram o poder a 15 de novembro de 1889 , o fim da herança colonial, a industrialização, o progresso da democracia. Era o mesmo ideal que, durante um século, todas as gerações de revolucionários agitaram. A República sintetizava-o. (...) O Brasil viveu momentos de delírio. Queria romper com tudo que lembrasse o passado (Moniz Bandeira, 1973, p.133-4).

Dessa forma, a política externa do governo provisório providenciou uma aproximação acelerada com os Estados Unidos.

Em 31 de janeiro de 1891, Salvador de Mendonça, responsável pela nova representação brasileira na Conferência Interamericana (1899-1890), assinou um acordo aduaneiro livre-cambista com os Estados Unidos, que nada mais era que a reedição do zollverein proposto por Cleveland e recusado pela Monarquia em 1887. Benjamin Constant, o novo Ministro da Guerra, irá manifestar sua adesão à Doutrina Monroe, “embalado pela retórica de unidade institucional do continente”. Em 1893, Floriano Peixoto contará com o apoio decisivo da esquadra estadunidense sob o comando do

\footnotetext{
${ }^{3}$ A expressão se refere genericamente a termos como pan-germanismo, pan-americanismo, paneslavismo, etc.
} 
Almirante Benham para neutralizar a Revolta da Armada, no mesmo ano em que a obra “Ilusão Americana” do monarquista Eduardo Prado será confiscada no Rio de Janeiro (Moniz Bandeira, 1973, pp.135-140 e pp.145-148; Bueno, 2003, p.53-55). A nova preocupação da política hemisférica de Washington era amparar a expansão de suas finanças e principalmente de seu comércio - com a criação da União Internacional das Repúblicas Americanas, em 1890 -, e não se verificava, para esse propósito, objeção real dos interesses britânicos, que então priorizavam a rivalidade européia e encontravam-se dependentes demais do comércio norte-atlântico para arriscar uma ruptura com os Estados Unidos.

Portanto, o período que vai da Proclamação da República à I Guerra Mundial assinala uma transição hegemônica de natureza política, refletida na capacidade de coerção e de dominação da potência ascendente e nas "funções ideológicas e educativas" que fazem com que a "sociedade não seja apenas comandada, mas também dirigida” (Macciocchi, 1977, p.150). No período em questão, contudo, não se deve menosprezar o fato de que economicamente a Grã-Bretanha permanece como referência externa do Brasil, principalmente através dos fluxos de capital. Nesse sentido, a notável expansão financeira dos ingleses nas décadas de pan-americanismo deve ser interpretada segundo o que Braudel apelidou de "sinal do outono" de uma hegemonia declinante, em que a reprodutibilidade do capital produtivo fica muito aquém da especulação e do crédito (Arrighi, 1994; Arrighi e Silver, 2001).

Feita essa apresentação, precisamos esmiuçar as nuanças do pan-americanismo na jovem República, fundamentalmente para não generalizarmos o radicalismo do governo provisório. Passado o surto inicial de americanização, opera-se um reequilíbrio com a tradição europeísta da oligarquia brasileira, pois, como sabemos, “os 
republicanos de 1889 imitaram Jefferson e Hamilton com sotaque de Auguste Comte” (Moniz Bandeira, 1973, p.207). A saída dos militares, o recurso ao capital britânico para estabilização (funding loan, 1898) e a posse de Rio Branco na Chancelaria (1902) sedimentariam o pragmatismo da aliança norte-americana, que passaria a ser contrabalançada com as pendências sul-americanas (questão do Acre, 1903) e as relações européias (Conferência de Haia, 1907), nas quais o Brasil soube afirmar-se perante o grande aliado do norte. Além disso, é necessário notar que o intervencionismo de cunho imperialista dos Estados Unidos, inaugurado em 1898, reacendia o receio e o temor da absorção brasileira à vontade de Washington (Moniz Bandeira, 1973). Em 1902, o então presidente Roosevelt, em discurso ao Congresso norte-americano, lançaria as bases de seu “corolário”: “(...) a crescente interdependência e complexidade das relações internacionais, tanto políticas como econômicas, impõem cada vez mais às nações civilizadas e organizadas o exercício de sua própria política policial através do mundo” (apud Bueno, 2003, p.46).

Nesse ponto, compreendemos a centralidade da fase Rio Branco (1902-1912) no redimensionamento estratégico do pan-americanismo da Política Externa da República oligárquica (“velha”); segundo Manzur, “foi na medida em que se mudou a face da política interna, com realce para o predomínio das novas elites agrárias produtoras de café, que a política externa pode ser definida com maior clareza” (Manzur, 1999, p.38).

Rio Branco - monarquista, centralizador, liberal, unitário e geopolítico - soube captar essas novas forças do "interesse nacional” brasileiro e colocou a aliança panamericana em um novo patamar. Segundo Clodoaldo Bueno,

um dos pilares da política exterior de Rio Branco foi a amizade dos Estados Unidos, com a qual se contemplavam os interesses da agroexportação e facilitava-lhe o exercício de uma política subregional. (...) Embora o chanceler enxergasse os princípios de 1823 como um anteparo às agressões européias, não mantinha ilusões a 
respeito da atitude dos Estados Unidos, caso estivesse em jogo interesses concretos de cidadãos norte-americanos (Bueno, 2003, p.145-153).

Logo, a reorientação de Rio Branco na Chancelaria da República - a despeito de uma tão falada aliança com Argentina e Chile - foi fundamentalmente em detrimento dos hispano-americanos, colocando o Brasil em um nível de "civilização" que o aproximava da Europa e em uma política de poder que o aproximava dos Estados Unidos. É nesse marco que devemos inserir a elevação da representação em Washington ao nível de embaixada, em 1906, logo retribuída pelos norte-americanos. Essa interlocução privilegiada com os Estados Unidos também fica manifesta no caso das demonstrações navais argentinas em litoral brasileiro, contidas por um intermédio estadunidense em 1908, e no jogo de reconhecimento da República Chinesa, em que o Brasil - não estando envolvido diretamente na matéria - respaldou a posição dos Estados Unidos. Poderíamos, seguindo Eugênio Garcia, esquematizar a cooperação internacional Washington-Rio de Janeiro em três eixos principais: “a defesa contra eventuais pretensões imperialistas de potências européias, apoio político em meio a um ambiente hispano-americano hostil e garantia de manutenção do fluxo de exportações brasileiras para o mercado norte-americano” (Garcia, 2006, p.596). A diretriz lançada por Rio Branco não seria interpretada com tanta habilidade por seus sucessores, que levariam o pan-americanismo às raias do servilismo. Após a morte de Rio Branco, o novo ministro Lauro Müller precisou fazer frente a um dos mais intrincados problemas da relação bilateral: o programa de valorização do café paulista. Em 1912, o Departamento de Justiça dos Estados Unidos acusou o Estado de São Paulo de práticas monopólicas de manipulação dos preços do café, que era importado pelos Estados Unidos livre de tarifas alfandegárias. O mal-estar dos torradores norte-americanos com 
os cafeicultores brasileiros não iniciava ali e ali não se esgotaria. Contudo, fica claro que a posição brasileira estava demasiado frouxa para se contrapor à pressão norteamericana; o embaixador em Washington, Domício Gama, era uma “voz destoante” em defesa do "interesse nacional” e da "soberania” do país. Em verdade, tanto o Chanceler quanto o embaixador reivindicavam para si a herança de Rio Branco: o primeiro pelo pan-americanismo, o segundo pelo patriotismo. Ao final, a questão foi resolvida em favor do Brasil, sem que ele decididamente fizesse por tal ${ }^{4}$ : em 1913, por pressão do Departamento de Estado (dos EUA), o Departamento de Justiça retira ação contra o truste do café de São Paulo (Bueno, 2003, p.374-382).

Se a tônica dos vinte cinco anos em análise foi claramente o alinhamento político com a hegemonia ascendente, não podemos menosprezar dois grandes movimentos do período: primeiro, a primazia econômica da potência declinante e sua financeirização, e, segundo, a conquista gradual pelos estadunidenses de posições tradicionalmente britânicas na economia brasileira.

Na virada do século, a Grã-Bretanha estava política e militarmente envolvida em múltiplas disputas do tabuleiro mundial: a disputa com os franceses na África (de Fashoda, em 1898, à divisão entre Marrocos e Egito, em 1904), a ascensão imperialista do Reich alemão (da questão marroquina, em 1905-08, aos Balcãs, em 1908), a Guerra dos Bôeres na África do Sul (1899-1902) e o expansionismo japonês no Extremo Oriente. Assim, a Doutrina Monroe e o Corolário Roosevelt aliviavam os britânicos de defenderem seus interesses em mais um teatro de operações. Por outro lado, a presença de capital britânico na economia brasileira expandia-se fortemente, seja como investimento privado ou como financiamento público.

\footnotetext{
${ }^{4}$ A decisão norte-americana de apaziguar o conflito explica-se não só pelo apreço pelo café brasileiro, mas também pela crise política então vivida em relação ao México e pelo receio de guerra européia, que desestimulavam os Estados Unidos a angariar inimizades.
} 
à medida que as indústrias (da Grã Bretanha) perderam vigor, suas finanças triunfaram e seus serviços como expedidora, negociadora e intermediária do sistema de pagamentos mundial tornaram-se mais indispensáveis. Aliás, se algum dia Londres foi o verdadeiro eixo econômico do mundo, tendo a libra esterlina como sua base, foi entre 1870-1913 (Hobsbawm apud Arrighi, 2001, p.76-77).

No caso brasileiro, os ingleses não só exerceriam sua liderança financeira no período (cujo ápice é o funding loan obtido por Campos Sales em 1898), mas também manteriam sua liderança industrial até, grosso modo, a I Guerra Mundial, a ver pelo peso das importações britânicas entre 1899-1913 (Bueno, 2003, p.117-123; Garcia, 2006, p.670-671). A estabilização da economia brasileira é financiada com capital britânico, que ainda articula a maior parte do investimento direto estrangeiro e das importações manufaturadas. Por mais que, em 1910, os Estados Unidos detenham 31\% das reservas mundiais, era na City londrina que se centralizava o crédito e as operações financeiras, amplamente atreladas à libra. Nas palavras de Giovanni Arrighi, “graças à manutenção de sua centralidade nas redes de altas finanças, os Estados hegemônicos em declínio puderam tirar proveito [da] competição [das nações pelo capital circulante] e, com isso, passar por uma recuperação de seu poder decrescente” (Arrighi, 2001, p.282). Será somente com a I Guerra Mundial (1914-1918) que a Grã-Bretanha veria ruir os pilares de seu poder no Brasil, já que a eclosão do conflito “afetou diretamente os transportes marítimos, o fornecimento de importações e o emprego de capitais (Garcia, 2006, p.479).

O segundo movimento que propusemo-nos a analisar é a conquista de espaço pelos norte-americanos, que ocorre paulatinamente na virada do século e é alavancada com a I Guerra Mundial. Ainda que haja alguma discrepância de dados, é notável a consolidação das exportações brasileiras aos Estados Unidos, que, aprofundando a 
tendência iniciada na década de 1860, supera os 400 mil contos de réis em 1909. Em 1911-1912, os Estados Unidos absorviam cerca de 40\% do café exportado pelo Brasil e cerca de 36\% de suas exportações totais (concentradas no café, no cacau e na borracha). É importante notar que o crescimento da presença estadunidense se dá pari passu à expansão econômica alemã (cujo eixo são as importações industriais), lançando as bases da rivalidade inter-estatal que se desenrolará na década de 1930.

Mesmo que já significativa, é com a I Guerra Mundial que a presença econômica estadunidense no Brasil irá deslanchar. Politicamente, a adesão brasileira na guerra ao lado dos Aliados é um constrangimento da Política Externa incondicionalmente pan-americana de Müller, somado ao bloqueio continental do comércio alemão - que interrompera os laços que o Reich estabelecia no Brasil. A princípio atirado aos braços aliados, de dentro em pouco o Brasil irá ver-se abraçado pelos norte-americanos. No flanco comercial, a guerra inter-imperialista na Europa acelerou a penetração norte-americana no setor em que essa ainda era débil: as importações. Totalizando 9,6 milhões de libras em 1915, esse valor passaria a £15,8mi (1916) a £21mi (1917) e por fim a £51,9mi em 1920, enquanto que as importações britânicas atingiam, no mesmo ano, somente £27,2mi (Moniz Bandeira, 1973, p.191). Além disso, o período de 1914-1918 marcará o avanço do capital norte-americano para setores estratégicos da economia brasileira, como as telecomunicações, a mineração e as estradas de ferro - que haviam sido erigidos desde o século XIX sob capital britânico. Essa tendência acabou sendo estimulada pela Grã-Bretanha que, envolvida no esforço de guerra, impôs crescentes restrições ao comércio e à exportação de capitais (Bueno, 2003, p.470-476). 
Paralelamente, verifica-se que, logo nos primeiros meses de guerra, o vácuo deixado pelos capitais europeus será um objetivo estratégico dos Estados Unidos, que convocam oportunamente a I Conferência Financeira Pan-Americana para maio de 1915. No mesmo ano, instala-se a primeira filial no Brasil de uma instituição bancária estadunidense, o National City Bank, sediado no Rio de Janeiro ${ }^{5}$. Por volta de 1920 , a América Latina já abrigaria 99 instituições bancárias como essa (Garcia, 2006, p.333334).

Ainda que o fim do conflito tenha restabelecido algumas condições do status quo ante, não podemos negligenciar a magnitude histórica da I Guerra para a transição hegemônica da Grã-Bretanha para os Estados Unidos. É, seguramente, o momento em que a história mais se “acelera”, no qual um evento de "tempo curto" deflagra e radicaliza transformações estruturais de longa duração. Nas palavras de Moniz Bandeira, incrementadas com certa dramaticidade ou exagero, podemos resumir o que se pretendeu explicar aqui:

"a guerra imperialista subvertera todas as situações. O centro financeiro, em torno do qual girava o Brasil, deslocou-se de Londres para Nova York, de Lombard Street para Wall Street. Os Estados Unidos ocuparam a posição de primazia que a Inglaterra antes detivera. E de modo muito mais amplo e efetivo. Dominaram todo o comércio exterior do Brasil, das exportações de café e borracha, que há muito controlavam, às importações de produtos manufaturados. Estabeleceram, praticamente, o sistema de mercado fechado, que caracteriza a servidão. E depois encamparam as suas dívidas externas, contraídas com a Inglaterra. Mas também herdaram o ódio e o ressentimento do povo brasileiro contra seus antigos senhores. Antes, no Império, o Governo evitava os Estados Unidos, enquanto o povo os olhava com esperança e admiração. Depois, com a República, tanto mais o governo se aproximava dos Estados Unidos tanto mais o povo os recusava, desconfiado e hostil” (Bandeira, 1973, p.205).

\footnotetext{
${ }^{5}$ No mesmo ano, é inaugurada a Câmara de Comércio Brasil-Estados Unidos, no Rio de Janeiro. A Câmara sediada em São Paulo data de 1919.
} 


\section{1918-1930: Economia, política e cultura}

O período final da República Velha sedimentará as transformações tão abruptamente desencadeadas com a I Guerra Mundial, configurando muito claramente a disputa entre uma hegemonia conservadora e outra ascendente. O espaço deixado com a perda de poder econômico e político-ideológico da Grã-Bretanha será, nesse período, aproveitado sobremaneira pelos Estados Unidos, de forma que, quando a ascensão germânica na década de 1930 desafia sua influência, eles estejam em condições de prevalecer. Assim, analisaremos separadamente a relação do Brasil com a Grã-Bretanha e a relação com os Estados Unidos no período em questão.

A relação entre Brasil e Inglaterra no pós-I Guerra será marcada por um descompasso entre estoque e fluxo, isto é, havia, por um lado, uma herança de grande presença britânica na economia brasileira (principalmente nos investimentos diretos), o que gerava um movimento inercial nas relações bilaterais; por outro lado, verificava-se uma tendência ao declínio relativo do peso inglês em detrimento dos países ascendentes (EUA e Alemanha), o que estimulava politicamente o afastamento da velha potência hegemônica. O resultado desse descompasso será uma tentativa política da GrãBretanha de relançar sua parceria econômica com o Brasil, o que configurará, reconhecendo-se o caráter defensivo de tal iniciativa, um perfil conservador que irá progressivamente degenerando-se em fracasso e ceticismo. O ceticismo em relação à renovação da presença britânica no Brasil abriria espaço para a disputa entre EUA e Alemanha na década de 1930, enquanto lançaria as prioridades inglesas para regiões onde seu declínio não se havia consumado com tanta clareza. 
Avaliando-se os dados coletados por Eugênio Vargas Garcia, verificamos que há uma queda consistente no peso relativo da Grã-Bretanha em termos comerciais, acompanhada de uma queda no investimento direto, ainda que os ingleses mantivessem como os mais importantes inversores absolutos na economia brasileira. Além disso, percebemos, na década de 1920, um crescimento do capital britânico no financiamento da dívida pública brasileira, o que não nos deixa esquecer a centralidade de Londres na articulação financeira internacional (Garcia, 2006; p.655-671).

Diante desse quadro, os ingleses lançariam duas frentes para a recuperação de sua influência no Brasil: no comércio, a prioridade era reverter o quadro gerado pela guerra, e esse intento foi levado a cabo pela Missão liderada por Maurice Bunsen já em 1918; nas finanças, a posição britânica foi estruturada com a Missão Montagu de 192324, que combinava o desejo de cooperação econômica com um alto grau de ingerência e de fiscalização das contas públicas brasileiras. A arrogância tecnocrática dos banqueiros ingleses, liderados pela casa dos Rothschild, seria vista com hostilidade pelos brasileiros, azedando ainda mais a relação com os britânicos. É salutar que como potência conservadora, preocupada em zelar por suas posições no país, a Grã-Bretanha via-se muito comumente levada a exercer um papel negativo em prol do status quo. Grande parte da agenda britânica no Brasil era dedicada à defesa de empresas e súditos britânicos, processos legais, arbitragens comerciais, cobrança de dívidas e indenizações, e inúmeras outras reclamações (claims) contra o governo federal, Estados, municípios e empresas privadas (Garcia, 2006; p.149).

No campo comercial, a grande derrota política dos ingleses deu-se em 1923, quando Brasil e Estados Unidos aplicam o tratamento de nação mais favorecida (NMF) em seu comércio bilateral, negligenciando a antiga reivindicação britânica por esse status. Em termos históricos, verificamos que não há em 1923 as condições objetivas que haviam permitido, um século antes, que o “imperialismo de livre comércio” inglês 
obtivesse tratados desiguais a favor de suas manufaturas. O resultado disso é que os “interesses [da Grã Bretanha] na América do Sul iriam se voltar cada vez mais para a Argentina, onde a disputa com os EUA não indicava ainda um claro vencedor” (Garcia, 2006; p. 293-294).

Nas relações com os Estados Unidos, existem três dimensões a serem analisadas: a política, a econômica e a cultural. Ainda que elas insiram-se nas linhas gerais do argumento aqui desenvolvido, a forma como a hegemonia estadunidense amadurece historicamente não deve sugerir uma evolução linear ou uniforme em cada aspecto. Processos históricos com tal amplitude são por natureza contraditórios e irregulares; recuam, avançam e estagnam conforme a circunstância se apresenta, adquirindo uma complexidade muito maior do que uma simples tendência constante. Nosso esforço é substituir essa complexidade pela verificação de seus traços mais relevantes, que nos permitam perceber o movimento estrutural em curso.

Na dimensão econômica, o período final da república oligárquica brasileira foi fundamental para a consolidação e expansão dos interesses norte-americanos, muito além do tratamento NMF e dos avanços notados no período da Guerra. Na esfera produtiva, o período marca a investida dos grandes trustes norte-americanos no mercado brasileiro, sendo extensa a lista de empresas e setores envolvidos ${ }^{6}$. Os investimentos realizados no Brasil por capital estadunidense denotariam uma sensível elevação, passando de US\$ 50mi em 1913 para US\$ 476mi em 1929. Além disso, é na década de 1920 que os Estados Unidos estabilizariam sua liderança nas importações brasileiras, espaço em que as manufaturas inglesas desfrutavam de histórica supremacia. Na esfera financeira, os Estados Unidos passariam de um papel absolutamente coadjuvante (recém

\footnotetext{
${ }^{6}$ Para maiores detalhes, ver Moniz Bandeira (1973, p. 214) e Garcia (2003, p.661-663).
} 
projetado pela Conferência Financeira de 1915) para serem os detentores de 35\% da dívida pública brasileira em 1929, tendo os empréstimos de Wall Street ao governo federal sido 33,8\% superiores aos obtidos em Londres, no período de 1915-1930 (Moniz Bandeira, 1973; p.214-215, Garcia, 2006; p.333-346, Cervo e Bueno, 2008; p.206-207). Grosso modo, pode-se qualificar a década de 1920 como um aprofundamento da dependência assimétrica entre a economia brasileira, altamente especializada e instável, com o capitalismo norte-americano, em momento de franca extroversão imperialista.

No entanto, a dimensão econômica não pode ser dissociada da questão política da relação bilateral, que é onde se manifestam mais claramente as idas e vindas do recentramento hegemônico. Inicialmente, é necessário reconhecer que o fim da primeira República sedimenta os três eixos estratégicos de cooperação tácita entre Estados Unidos e Brasil, quais sejam (1) o monroísmo, (2) o apoio mútuo contra um hispanoamericanismo hostil e (3) o comércio bilateral, liderado pelo café. Esses eixos, herdados do período riobranquino, permitirão uma base comum de acordo para o alinhamento relativamente estável do Brasil aos vizinhos do Norte, mas não evitarão o surgimento de conflitos políticos, principalmente em torno de questões extra-hemisféricas. A “política de prestígio internacional” lançada por Artur Bernardes será razão de desavenças diplomáticas a partir da decisão brasileira de, em 1920, não se retirar da Liga das Nações como haviam feito os Estados Unidos. A ambição brasileira de ser o "porta-voz do pan-americanismo na Liga” contradizia o cálculo inicial de Washington, segundo o qual o Brasil seria mais uma voz para a posição norte-americana. Esse desagrado com o “ufanismo diplomático” brasileiro seria ainda maior com a não-adesão do Brasil, já no 
governo de Washington Luís, ao Pacto Briand-Kellogg de 1926 (Cervo e Bueno, 2008, p.229; Burns, 1990, p.399-400).

O outro ponto de conflito político fundamental é o ressurgimento da questão da valorização do café, que colocará em questão o terceiro eixo de cooperação estratégica entre os dois países. A partir de 1924, a política conveniada em Taubaté (1906) passou a ser responsabilidade dos governos estaduais, graças às crescentes dificuldades de financiamento do Governo de Bernardes; foi criado, para tal, o Instituto Paulista para a Defesa Permanente do Café. Em razão da manipulação de preços pelos produtores, os torradores (intermediários) estadunidenses apresentaram uma petição ao então Secretário de Comércio H. Hoover para que intercedesse contra o Instituto monopolista. Isso ensejou a Missão da Associação dos Torradores de Café (Junho/1925), que, com o suporte político de Hoover, veio ao Brasil negociar com os cafeicultores. Ao contrário dos banqueiros britânicos no ano anterior, os intermediários estadunidenses optaram por um tom mais conciliatório, pois eles não estavam, segundo Eugênio Vargas Garcia, “em condições de pressionar até o limite por uma alteração radical da política brasileira”; em outras palavras, estavam constrangidos pela essencialidade das exportações brasileiras de café (Garcia, 2006, p.313-332).

Ademais, o episódio dos torradores de café nos revela uma dinâmica relevante da disputa inter-capitalista pelas altas finanças no período. Em 1925, Hoover ameaça os produtores brasileiros com um corte de financiamento, caso mantivessem a política de valorização do café; impossibilitado de obter capitais em Wall Street, o Instituto não hesitará em recorrer à City londrina, recebendo um empréstimo de £10mi no início de 1926. Não demoraria a que o inverso ocorresse. Após a crise na Liga das Nações de Março de 1926, quando o Brasil veta a entrada da Alemanha no Conselho da Liga, os 
ingleses decidem, como represália ao governo brasileiro, proibir os banqueiros londrinos de efetuar o empréstimo que o governo de Bernardes buscava. Os banqueiros estadunidenses, por seu turno, receberiam com agrado a decisão do Foreign Office britânico, concedendo US\$60mi ao governo insolvente. O fracasso da tentativa de “coerção creditícia” das potências imperialistas revela certa margem de manobra do Brasil, que barganhava entre uma potência hegemônica declinante, altamente financeirizada, e uma hegemonia ascendente, então em processo de internacionalização de seus capitais ${ }^{7}$.

A penetração cultural, nosso último item, concatena e sedimenta a presença política e econômica dos Estados Unidos no Brasil. O período final da república oligárquica irá testemunhar a segunda onda de “americanização” do país ${ }^{8}$, com o alvorecer do cinema industrial de Hollywood (em 1926, 95\% dos filmes exibidos no Brasil eram norte-americanos), do estabelecimento das redes de notícias (UPI em 1918, AP em 1919), da dispersão do gramofone e do jazz, do fortalecimento das fundações Ford e Rockefeller, da pedagogia americanizada de Anísio Teixeira, do proselitismo protestante, das escolas americanas (secundárias e superiores) e das ACM’s (Associação Cristã de Moços) (Moniz Bandeira, 1973, p.206-209; Garcia, 2006, p.133-145). No entanto, talvez o elemento mais relevante, em termos culturais e econômicos, seja a introdução no Brasil do automóvel, que, no período 1913-1928, foi a principal importação brasileira dos Estados Unidos. No pós-I Guerra, as montadoras norteamericanas (Ford e General Motors) instalar-se-iam em São Paulo, ganhando progressivamente o mercado de suas concorrentes francesas, alemãs e inglesas. No governo de Washington Luís, segundo o qual “governar é abrir estradas”, o Brasil

\footnotetext{
7 Para maior detalhe a respeito dos empréstimos obtidos pelo Brasil no período, consultar os dados disponíveis em Garcia (2003, p.555-663).

${ }^{8}$ Sendo a primeira, como vimos, no período posterior à Proclamação da República.
} 
chegou a ser o quarto maior comprador dos automóveis exportados dos EUA. Como nota Eugênio Vargas Garcia,

a ascensão irresistível do rodoviarismo nos anos 20, no qual os
Estados Unidos apareciam como líder natural, não poderia simbolizar
melhor as mudanças de longo prazo na infra-estrutura brasileira e a
transição de poder que se estava desenvolvendo no plano global das
Ilhas Britânicas para a América do Norte” (Garcia, 2006; p.144-145).

\section{Conclusões}

A hegemonia norte-americana no sistema mundial fundamentou-se no pragmatismo da hegemonia militar (tipificado na contenção soviética) e no idealismo político da Revolução Americana (tipificado no Sistema-ONU), tendo a II Guerra Mundial sido um momento-chave para sua construção histórica. O argumento aqui desenvolvido conclui que, na realidade brasileira, esses dois pilares de hegemonia se erigiram algumas décadas antes, durante a república oligárquica dos cafeicultores. Sendo assim, a I Guerra Mundial foi o ponto de inflexão. O pragmatismo militar norteamericano foi disseminado pelo Brasil e pela América Hispânica no início do século XX, através do Corolário Roosevelt (big stick), que garantia a ameaça e o emprego da força para consubstanciar a liderança hemisférica. Já o idealismo político foi amadurecido com as Conferências Pan-Americanas, institucionalizado na Secretaria Internacional das Repúblicas Americanas e sublimado nos ideais de república, de respeito ao Direito Internacional, de anti-colonialismo e de prosperidade pelo comércio. Essa foi a referência ideológica com que os Estados Unidos legitimaram sua hegemonia no Brasil e na América Latina, sendo posteriormente universalizada e globalizada. É recorrente a idéia de pensar a Secretaria Pan-Americana como um embrião da 
Organização dos Estados Americanos de 1948. No entanto, nossa argumentação sustenta que a Secretaria é muito mais um embrião regional do princípio das Nações Unidas, sendo para ele mais relevante, talvez, que o fundamento ideológico da experiência da Liga das Nações. Enquanto a hegemonia norte-americana iria se sustentar em termos globais com base no "perigo vermelho" e na bipolaridade maniqueísta da Guerra Fria, a consolidação continental de sua hegemonia far-se-á em contraposição ao “perigo alemão” do início do século. Nosso estudo sugere que o fim da I Guerra Mundial gera um processo de recentramento hegemônico nas relações internacionais do Brasil que é análogo àquele ocorrido após a II Guerra em todo o sistema mundial. Isso ocorreu porque as funções materiais e ideológicas da hegemonia já estavam relativamente maduras em 1918.

Nosso estudo da economia e da política externa brasileiras oferece duas razões essenciais para esse fenômeno: uma geoestratégica e outra econômica. A primeira é que o Brasil encontra-se em uma região considerada vital para os Estados Unidos e reconhecida como tal desde a Doutrina Monroe. Enquanto a Grã-Bretanha administrava seu império colonial afro-asiático, os Estados Unidos capitalizavam seus vizinhos do Sul; era de se esperar, portanto, que o poder norte-americano se consolidasse primordialmente na América Latina. A segunda razão, de cunho econômico, é mais específica do Brasil. Desde a liberalização da entrada do café no mercado dos Estados Unidos (1870), desenvolveu-se uma brutal complementaridade econômica entre os dois países, sendo notável o crescimento do comércio bilateral nessas quatro décadas. O setor cafeeiro do Sudeste do Brasil foi alavancado pela popularização do consumo de café nos Estados Unidos, e essas exportações foram deliberadamente estimuladas graças 
a uma política comercial favorável ao Brasil $^{9}$ que culminou no estatuto de NMF de 1923. A percepção dessa complementaridade gerou uma identificação muito mais intensa com a hegemonia ascendente, favorecendo um alinhamento político aos Estados Unidos tão estável que isolava o Brasil na América do Sul.

Portanto, nossas conclusões até aqui podem ser resumidas no que segue: a transição hegemônica mundial foi precipitada na sociedade brasileira por sua posição geopolítica e pela complementaridade econômica que a vinculava aos Estados Unidos, de modo que já se estabelecia aqui, ao longo da República Velha, os fundamentos político-militares e ideológicos da hegemonia norte-americana.

No entanto, a compreensão da transição hegemônica em um país periférico implica também analisar suas repercussões e seus significados macro-históricos, e quanto a esse ponto elencamos três transformações estruturais da história brasileira. A primeira é o processo de transição das elites brasileiras, na qual o declínio definitivo da “sacarocracia” nordestina e da elite europeísta carioca foi acompanhado da ascensão dos cafeicultores paulistas, que viriam a ser a ponta de lança da industrialização brasileira. Vale lembrar que foram esses cafeicultores que assinaram o Manifesto Republicano de 1870, assim como exportavam sua produção para os Estados Unidos e comprariam seus automóveis de montadoras estadunidenses. A segunda transformação estrutural são precisamente os automóveis. O projeto britânico para o Brasil era essencialmente de uma malha ferroviária movida a carvão, e essa diretriz havia sido reafirmada pela Missão Montagu de 1823-24. No entanto, a ascensão da influência norte-americana trouxe a obsolescência das ferrovias e o fortalecimento do padrão rodoviário movido a petróleo, que seria massificado com o capital estrangeiro na década de 1950. Para quem

\footnotetext{
${ }^{9}$ A tarifa McKingley, que impôs altas taxas alfandegárias nos EUA de 1890-1894, não foi aplicada ao café e ao açúcar. O mesmo ocorreu com a Tarifa Dingley, de 1897, que elevava o protecionismo para todos os países latino-americanos à exceção do Brasil.
} 
menospreze a relevância da alteração do sistema nacional de transportes aqui descrito, basta ver o desafio colocado hoje pela substituição do modelo baseado em combustíveis não-renováveis.

A terceira transformação estrutural relacionada com a transição hegemônica é a nova distribuição relativa de poder na América do Sul, em especial no que tange o equilíbrio Brasil-Argentina. A Argentina foi a grande potência regional até as primeiras décadas do século XX, sendo a economia mais desenvolvida, a sociedade com maior educação, o território com melhor infra-estrutura e possivelmente as forças armadas mais bem preparadas. O Brasil, por seu turno, acelerara sua modernização no final do século XIX e tornara-se, desde 1889, o principal interlocutor dos Estados Unidos na região. Desenvolvendo-se associado à hegemonia ascendente, o Brasil logo superará militar e economicamente os vizinhos do Prata e colocar-se-á como a principal potência sul-americana, enquanto os argentinos desenvolverão o saudosismo de sua belle époque.

Ainda que possamos ter aqui lançado algumas luzes sobre esse objeto tão multifacetado e intrigante, muitas questões inevitavelmente ficam ainda por responder. Uma relação aparentemente sugestiva, e que demandaria maior estudo, é a possível conexão entre hegemonia mundial e forma de governo. Tendo passado alguns séculos como colônia, o Brasil independente irá abraçar a monarquia parlamentar com o mesmo vigor com que será absorvido pelo capitalismo inglês; irá criar uma república federativa quando os Estados Unidos tornam-se o farol do progresso e terá um deslize autoritário na década de 1930, quando a Alemanha reivindica sem sucesso a hegemonia mundial. Outro problema de estudo seria a transição hegemônica mundial em outros espaços periféricos, com um particular interesse para a realidade latino-americana. Os resultados 
CADERNOS DE RELAÇÕES INTERNACIONAIS, v. 4, n.1, 2011

podem ser úteis tanto para analisar criticamente a história desses espaços como também para discutir e reavaliar as teorias de transições hegemônicas com que trabalhamos. 


\section{Referências}

ARRIGHI, Giovanni. O longo século XX: dinheiro, poder e as origens do nosso tempo. Rio de Janeiro: Contraponto; São Paulo: Editora UNESP, 1996.

ARRIGHI, Giovanni; SILVER, Beverly. Caos e governabilidade no moderno sistema mundial. Rio de Janeiro: Contraponto: Editora UFRJ, 2001.

MONIZ BANDEIRA, Luiz Alberto. Presença dos Estados Unidos no Brasil: dois séculos de história. Rio de Janeiro: Civilização Brasileira, 1973.

BUENO, Clodoaldo. Política Externa da Primeira República: os anos de apogeu (1902-1918). São Paulo: Paz e Terra, 2003.

CERVO, Amado; BUENO, Clodoaldo. História da Política Exterior do Brasil. Brasília: Editora Universidade de Brasília. $3^{\mathrm{a}}$ Edição Ampliada, 2008.

BURNS, Bradford. As relações internacionais do Brasil durante a primeira república. In FAUSTO, Boris (org.) História Geral da Civilização Brasileira, Tomo III $2^{\circ}$ vol., O Brasil republicano: sociedade e instituições (1889-1930). Rio de Janeiro, Editora Bertrand Brasil, 1990, p.378-400.

DORATIOTO, Francisco Monteoliva. O Império do Brasil e as grandes potências. Em MARTINS, Estevão Chaves de Rezende (org.) Relações Internacionais: visões do Brasil e da América Latina. Brasília: FUNAG/IBRI, 2003, p. 133-152.

GARCIA, Eugênio Vargas. Estados Unidos e Grã-Bretanha no Brasil: transição de poder no entreguerras. Contexto internacional, vol. 24, n. 1, 2002, pp. 41-71.

Entre América e Europa: a política externa brasileira na década de 20. Brasília: Editora Universidade de Brasília: FUNAG (Fundação Alexandre Gusmão), 2006.

GRAMSCI, Antonio. Os intelectuais e a organização da cultura. Rio de Janeiro: Civilização Brasileira, $4^{\mathrm{a}}$ Edição, 1982. 
GUIMARÃES, Samuel Pinheiro. Quinhentos anos de periferia: contribuição ao estudo

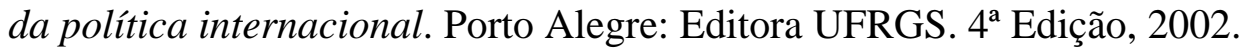

MACCHIOCCHI, Maria-Antonietta. A favor de Gramsci. Rio de Janeiro: Paz e Terra, $2^{\mathrm{a}}$ Edição, 1977.

MANZUR, Tânia Maria Pechir Gomes. Opinião pública e política externa do Brasil do Império a João Goulart: um balanço historiográfico. Revista Brasileira de Política Internacional, $\mathrm{n}^{0}$ 42, vol.1, 1999 pp.30-61.

MOURA, Gerson. O Tio Sam chega ao Brasil: a penetração cultural dos Estados Unidos no Brasil. São Paulo: Brasiliense. 2a Edição, 1985. 